\title{
Ensuring safety of people in case of severe floods: feasibility and relevance of vertical evacuation strategies in high population density areas
}

\author{
Rodolphe Pannier ${ }^{1, a}$ \\ ${ }^{1}$ CEPRI, BP 2019, 45010 Orléans cedex 1, France
}

\begin{abstract}
When a major flooding event is expected the authorities in charge of the crisis management often consider bringing people to safety by making them leaving temporarily the threatened area before the onset of the flood. This strategy is called "horizontal evacuation". It has to be distinguished from "vertical evacuation", which means that people reach a shelter above the wtaer level within the flood area. Vertical evacuation is often the spontaneousbehaviourof people who are surprised by the flood and are trying to reach a tree, a floor upstairs, a roof of a building etc. in order to get away from the rising water. But vertical evacuation could also be consideredas an alternative strategy to horizontal evacuation when moving outside the flood area is neither a faisible nor a relevant option, for example in high-population density areas. In order to be a credible alternative to horizontal evacuation, vertical evacuation has to be carefully planned. This paper aims to explain why horizontal evacuation is not always a suitable option in case of major flood and to explore under what conditions vertical evacuation can be a relevantalternative solution to horizontal evacuation. It also adresses some general recommendations about how to prepare a vertical evacuation strategy..
\end{abstract}

\section{Leaving the threatened area when a major flood is expected is not always the most suitable option}

When a major flood is expected, the crisis managers strategy for ensuring population safety is often based on a preventive evacuation of people to the outside the flood zone.

Evacueesare temporarily rehoused by their own (in hostels, at friends or relative's house etc.) or with the support of the public authorities and the nongovernmental organisations (NGO). This strategy is called « horizontal evacuation ».

\subsection{Advantages of horizontal evacuation}

A preventive horizontal evacuation appears to be a logical and common-sense solution in order to reduce risk for people lives sincethe population moves away from the danger area. Preventive horizontal evacuation also preserves emergency workers health by limiting potentially hazardous search and rescue operations in the flood area, since the zone is in theory emptied of its inhabitants ${ }^{1}$.

Lastly, when implementing a preventive horizontal evacuation, the evacuees are taken in charge outside the danger area, in a relatively safe environnment. It facilitates the implementation of the first measures of support and care provided by authorities, emergency services and $\mathrm{NGO}^{2}$.

However, despite these potential benefits, horizontal evacuation strategy is neither a trivial nor a harmless option.

\subsection{Constraints of horizontal evacuation}

Horizontal evacuation strategy involves various and potentially significant disadvantages and risks for people and authorities.

People on the move are extremely vulnerable to floods. For example, in United States, $60 \%$ of fatalities during a flood disaster between years 2000 and 2011 are related to the use of a vehicle ${ }^{3}$. So, the time available for leading the whole evacuation process has to be sufficient for all persons concerned can leave the flood areawithin the time available between warning and the onset of the flood.

. In case of flash flooding in urban area, preventive horizontal evacuation will be very hard to apply.

During the evacuation process, the risk of car accident is higher than usual because of the overall stress for drivers and the difficulties in managing the road traffic in a context of major flood crisis. It may be aggravated by adverse weather conditions during the movement of people. When inhabitants massively left the Houston area before the landfall of Hurricane Rita in september 2005,

\footnotetext{
a Corresponding author: rodolphe.pannier@cepri.net
} 
only six people died because of the hurricane while hundred people died incar accidents or due to the severe heat wave that had been affecting the State of Texas at the same time ${ }^{4}$.

In the case of coastal flooding, horizontal evacuation is a risky strategy because of the storm and its violent and high-speed wind that canbring down trees and other materials on the evacuation roads and on people. After the landfall of Storm Xynthia that flooded parts of the french Atlantic coast and killed 47 persons, a meteorologist explained: «Should authorities have to order the massive evacuation of the entire coastal area? The answer isn't easy. It's another very significant risk to bring on the road thousand of vehicles while winds are blowing of up to $160 \mathrm{~km} / \mathrm{h} »^{5}$.

Managing a massive horizontal evacuation requires very important human, technical and logistical means in order to support the evacuation process and more particularly to support people who aren'table to move (residents in hospital, prisoners, people without means of transport) and who are not able to rehouse by their own. In France, evacuation plans are built on the hypothesis that between $25 \%$ and $33 \%$ of evacuees will need a specific support to move away from the flood zone or to rehouse ${ }^{6}$.

Massive horizontal evacuation may generate important economic losses because people leaving the area stop working. In the Paris area, a massive horizontal evacuation due to a major flood of the Seine river would impact significantly the french national economic activity for the reason that the Paris area creates $1 / 3$ of the Gross Domestic Product.

The departure of people may encourage violence and civil disorder: e.g. the looting of unoccupied houses, shops and public facilities.

A massive horizontal evacuation of an urban area has to be initiated early at a time when the threat is not yet certain. It increases the risk of false warnings while a massive horizontal evacuation doesn't allow for mistakes.

The consequences of a «false alarm » leading to an unjustified massive horizontal evacuation would be disastrous for people, economy and credibility of authorities. Next time, people will probably be reluctant to trust authorities and to follow the evacuation orders. Eventually, the crisis in New Orleans due to 2005 Hurricane Katrina and in New York caused by Hurricane Sandy in 2012have illustrated that a massive horizontal evacuation is almostalways incomplete. Indeed, some people stay in the flooded area either because they don't want to leave or because they aren'table to do it. An incomplete horizontal evacuation with an unprepared maintenance of people in the flooded zone can lead to disaster. Before the landfall of Hurricane Katrina in New Orleans in august 2005, 360000 of the 440000 inhabitants had followed the preventive evacuation command given by authorities while almost 80000 people had decided or had been forced to stay in the city. More than 1300 persons died in New Orleans when the levees broke. The rest of the population escaped from the rising waters on the roofs of houses or in overcrowded and unsuitable buildings sites, and survived in terrible conditions ${ }^{7}$.
Considering all these constraints, the implementation of a massive horizontal evacuation is not systematically the most suitable and realistic option when a major flood is expected.

This is particularly the case in high population density areas. A massive horizontal evacuation would be a very complex and hazardous operation regarding the size of the population concerned, the risk of traffic congestion, the potential economic impacts of the stop of the activities, and the colossal means needed to support such a large scale operation.

\section{Vertical evacuation: an alternative strategy to horizontal evacuation}

Vertical evacuation can be defined as the movement of people within the flood prone area with the aim of reachinga relatively safe place above the water level.

Vertical evacuation constitutes the spontanous response of people surprised by the flood and trying to reach a tree, a floor upstairs, a roof of a building etc. in order to get away from the rising water.

Beside this individual last resort reflex, vertical evacuation canalso be adressed as aplanned strategy when horizontal evacuation is neither a faisible nor arelevant option.

It is already the case in the Netherlandswhere less than $20 \%$ of the population is expected to be able to evacuate before the onset of a flood in some coastal areas ${ }^{8}$.

\subsection{Advantages of vertical evacuation}

The implementation of a vertical evacuation strategy has many advantages.

Vertical evacuation reduces time needed to bring people to safety compared to horizontal evacuation. It provides an additionnal time for authorities and experts to evaluate the reality of the threat and to prevent unnecessary alarms.

Vertical evacuation reduces the movements of people and so limits their exposure to flood, traffic accidents and weather related threats. It also increases the fluidity of trafic and so facilititates the action of crisis and emergency services.

This strategy limits the number of people in need to be supported and rehoused by authorities.

Maintaining people within the flooded area limits the risk of looting. Compared to horizontal evacuation, vertical evacuation reduces economic losses because a part of the population will continue to work. In case of unneccessary alert, socio-economic disruptions would be less damaging than in the case of a massive horizontal evacuation.

\subsection{Conditions for implementing vertical evacuation}

\subsubsection{Sheltering at home}


In some cases, people can find shelter at home by going upstairs.

This way of sheltering necessitates a floor with a roomlocated above the level of water expected (houses with two floors, houses on stilts).

The part of the house used as shelter must belarge enough to receive all the people concerned. The humanitarian standards definea minimum of $3,5 \mathrm{~m}^{2}$ per person for a short-term stay ${ }^{10}$.

Sheltering at home is suitable only if the house is built with the sufficient strength to resist the effects of the flows and the shocks related to materials and debris carried by the water.

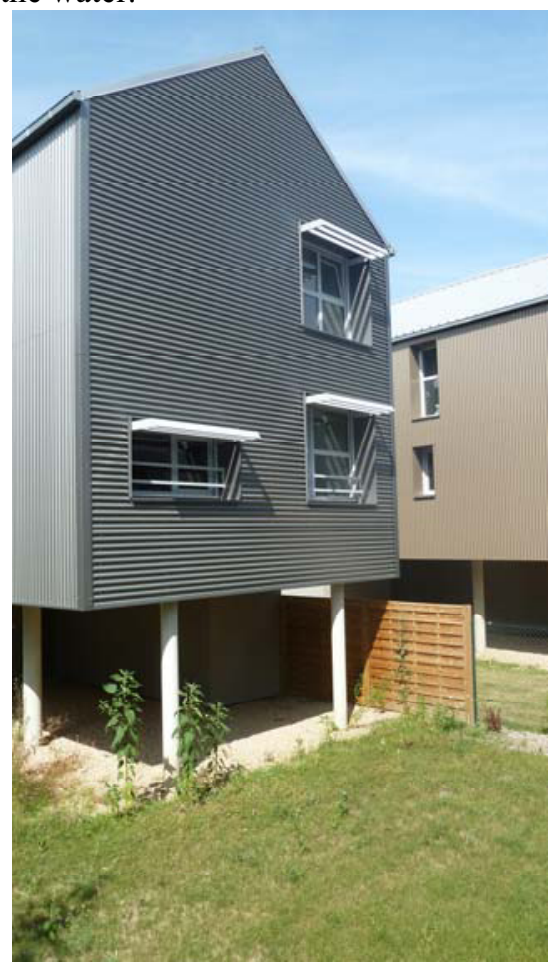

Figure 1 : Example of two-storey house built on stilts. Saint-Pierre-des-Corps, France (CEPRI)

The house needs at least one access to the outside for people to go out and for emergency services to get inside if needed.People staying at home should have enough water and food or shouldbe able to find easily supplies near their house (authorities can plan temporary supplies centers accessible with elevated paths, amovible bridges etc.). A system of home-based supplying can be planned too.

Technical networks should continue to work. In case of network disruptions, alternative solutions will have to be anticipated at least for vital needs (e.g. providing water bottles in case of disruption of drinking water systems).

Houses must not to be located close to sensitive infrastructures that may causecascading effects if flooded (explosion, heavy pollution, fire, toxic clouds etc.).

Sheltering at home is not always a feasible solution, for instance, for those who are far from home when the flood occurs, for people who live in house on one level without safe room above the water and for vulnerable persons with special needs who are not able to stay home with degraded living conditions (elderly people, sicky persons, people with diabilities etc.).

\subsubsection{Evacuating to collective shelters}

Authorities can offer solution to people who don't want or are not able toshelter at homeby planning vertical evacuation into the upper levels of collective buildings.

This strategy is implemented in Japan and United States as one solution for ensuring people safety in case of tsunami.

In Japan, during the tsunami of 11th march 2011, 2500 people from the city of Kessennuma found temporary shelter inside the eleven high public building planned by local authorities to be used in case of disaster ${ }^{11}$.

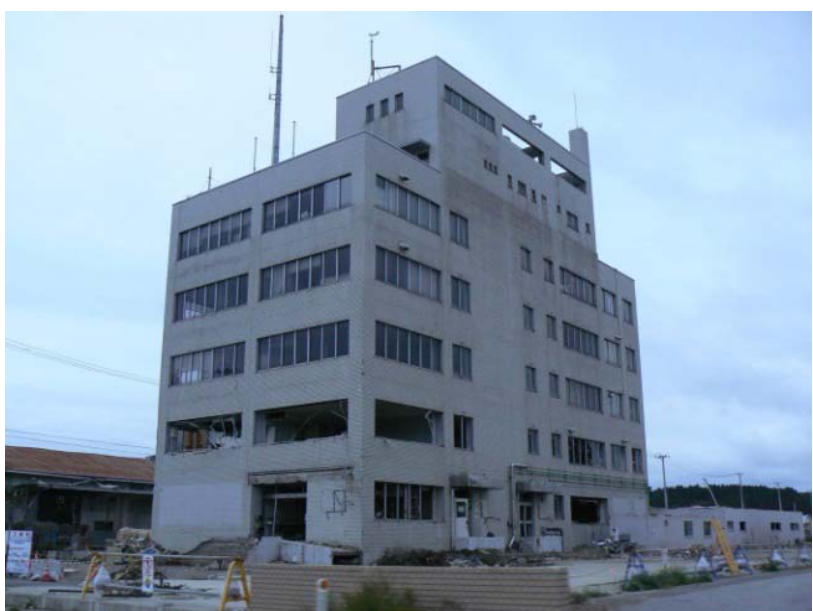

Figure 2: The National Government office of the city of Kessennuma, Japan, where 120 people took refuge from the March 11th tsunami (Fraser and al., 2012)

Vertical evacuation to collective buildings may also be invistigated as a strategy to cope with major flood in urban areas.

The vertical evacuation strategy can be based on the construction of new structures or organised with existing buildings.

The collective shelters used for vertical evacuation may serve various purposes. It is possible to add other functions to the building when not serving as a shelter in order to optimize investments and to support local development

This multi-use shelter concept was developped in particular by the partners of the Floodprobe FP 7 Project and is known as « smart shelters ${ }^{12}$.

An example of "smart shelter » is the Airport of Rotterdam planned to act as a shelter suitable to protect and support 50000 inhabitants from neighbourhoods in case of major flood ${ }^{13}$.

A crisis management strategy based on the use of collective shelters within the flooded area involves various risks. Failures in implementation of a vertical evacuation can be disastrous as illustrated by the humanitarian crisis inside the New Orleans Superdome stadium in august 2005 after the landfall of Hurricane Katrina. 
The Superdome stadium had been choosen by authorities in the nineties to be a « refuge of last resort » in case of hurricane for those who weren't able to leave the city preventively. It was previously used in year 1998 during Hurricane Georges and in year 2004 during Hurricane Ivan with some success.

Before the arrival of Hurricane Katrina in august 2005, the Superdome stadium had been opened and provided with food and water for an expected population of several thousands of people for two to three days. But the levees broke and $80 \%$ of the New Orleans was flooded. Almost 25000 survivors took refuge inside the stadium. As the Supedome was inadequate in relation to to the crowd that came, living conditions soon deteriorated. As the power went out, air conditioning and water system stopped too. The situation in the overcrowded and overheated stadium dramatically aggravated leading to horrible live conditions for days ${ }^{14}$.

In order to avoid such a disaster, the use of collective shelter has to beplanned with care.

Crisis mangers should build on the work done about vertical evacuation during a tsunami emergency. For examples, the «Guidelines for Design of Structures for Vertical Evacuation from Tsunamis » of the Federal Emergency Management Agency (FEMA) of UnitedStates of America provides recommendationsn about desingning and locating tsunami vertical evacuation structures $^{15}$.

The «Handbook of Tsunami Evacuation Planning » of the Joint Research Centre of the European Commission provides a methodology of tsunami evacuation plan generation ${ }^{16}$.

If the characteristics of river and coastal floods are different from tsunami flooding, some of these recommendations are applicable to flood vertical evacuation strategies.

The key point of a vertical evacuation strategy is the determination of the buildings that will be used as collective shelters.

Vertical evacuation buildings must have sufficient height for people to elevate above the maximum level of water expected on the site

The structures mustbe built with the sufficient strength to resist the effects of the the flows and the schocks related to materials carried by the water.

The areas of buildings located above the level of water must be large enough to receive the number of people concerned. Of course, the sizing of the vertical evacuation structures will depend on the expected number of occupants, the type and the duration of stay in the shelter.

The number of occupants will depend on the number of people exposed to flood and the spacing and number of vertical evacuation structures located in the area.

Duration of occupancy will depend on the nature of the flood and the intended function of the facility ${ }^{17}$.

A vertical evacuation structure must provide decent living conditions and adequate services to evacuees for their intended length of stay.

The longer the anticipated stay in a shelter, the greater will be the needs in terms of space per person and comfort. . As a short term refuge for healthy and uninjured people, services can be minimal with only limited space (minimum of $3,5 \mathrm{~m}^{2}$ per occupant ${ }^{17}$ ) and basic sanitation needs. This living space per person should be significantly adjusted up for a longer stay to accomodate beds and supplies or if the shelter is intended to house sick or injured people.Technical networks have to continue to operate inside the building. If not, authorities would have to think about alternative solutions to meet at least vital needs of people.The number and the location of flood vertical evacuation structures will depend on the size of the area and the number of people exposed to flood. Vertical evacuation structures should be located such that all persons concerned can reach the structure within the time available between warning and the onset of the flood.

Vertical evacuation structures should be located away of sensitive infrastructures that may cause cascading effects if flooded.

Authorities should provide support to vulnerable people who are not able to find and to reach the shelters by their own.

Road to the vertical evacuation structure should be easily accessible and well-marked.

People and emergency services have to be informed with clear messages about the buildings choosen to be used as collective shelters in case of flood, their location, the itinaries, and the living conditions and rules inside (capacities of reception, support and supplies provided, if pets are allowed or not etc.).

\section{Conclusion}

In case of major flood, neither horizontal nor vertical evacuation provides an easy solution. Both involve advantages and risks for people and authorities.

The choice between horizontal and vertical evacuation needs to be made with an analysis comparing risks of horizontal evacuation with risks of vertical evacuation in the flood area.

The choice would be based on the forereseeability of the flood and time available between the warning and the onset of the flood, risk for human life in the flood area, density of population, risk of traffic congestion, means available to support the process etc.

In many cases the crisis management strategy will combine both horizontal and vertical evacuation.

In high population density areas, vertical evacuation will likely constitute an important part of the strategy as horizontal evacuation willbe very difficult to implement at a large scale.

Given what is at stake, vertical evacuation needs to be anticipated, well planned and adressed closely related to other fields of the flood risk management.

Planning vertical evacuation should be supported with significant measures aiming to prepare the inhabitants to the good behaviours for ensuring their safety within the flood area.

Similarly, adapting urban planning to flood and reducing vulnerability of houses, networks, public services to the risk willcontribute to facilitate the 
implementation of vertical evacuation and the ability of people to cope with the risk within the flood area.

\section{References}

1, 2, 5, 6, 13: Centre Européen de Prévention du Risque d'Inondation (2014). L'évacuation massive des populations. Les territoires face à l'inondation. Les guides du CEPRI. 98 pp.

3: National Oceanic and Athmospheric Administration's National Weather Service http://www.nws.noaa.gov/oh/hic/flood_stats/recent_i ndividual_

deaths.shtml

4: Carpender, S. K., Campbell, P. H., Quiram, B. J., Frances, J., \& Artzberger, J. J. (2006). Urban Evacuations and Rural America: Lessons Learned from Hurricane Rita. Public Health Reports, 121(6), pp. 775-779.

7, 14 : U.S. House of Representatives (2006). A failure of initiatives. Final Report of the Select Bipartisan Committee to Investigate the Preparation for and Response to Hurricane Katrina. 364 pp.

8 : Rijkswaterstaat (2006). Veiligheid Nederland in Kaart: Modellering en Analyse van Evacuatie, dijkringen 7, 14 en 36. Report DWW-2006-007.

9: Velotti, L., Trainor J., Torres T., Kolen B., Engel K. (2012). Vertical Evacuation: Rethinking Urban, Rural and Social Space. Flood Preparedness in the Netherlands: A US Perspectiv, pp. 103-117

10, 18 : Projet SPHERE (2011). Charte humanitaire et les standards minimums de l'intervention humanitaire. $445 \mathrm{pp}$.

11: Fraser S., Leonard G.S., Matsuo I. and Murakami H. (2012). Tsunami evacuation: Lessons from the Great East Japan earthquake and tsunami of March 11th 2011, GNS Science Report 2012/17. 81 pp.

12: Deltares (coord.) (2013). Construction technologies for flood-proofing buildings and Infrastructures. Concepts and Technologies for Smart Shelters. FloodProBE report WP04-01-12-1. 33 pp.

15, 17 : FEMA (2008). Guidelines for Design of Structures for Vertical Evacuation from Tsunamis. FEMA P646 Report, prepared by the Applied Technology Council for the Federal Emergency Management Agency, Redwood City, California. 158 pp.

16: Joint Research Centre - Institute for the Protection and Security of the Citizen (2011). Handbook of Tsunami evacuation planning. Publications Office of the European Union. 54 pp. 